\title{
An outlook on comparison of hybrid welds of different root pass and filler pass of FCAW and GMAW with classical welds of similar root pass and filler pass
}

\author{
PRITESH PRAJAPATI, VISHVESH J BADHEKA and KUSH MEHTA* \\ Department of Mechanical Engineering, School of Technology (SOT), Pandit Deendayal Petroleum University \\ (PDPU), Raisan, Gandhinagar 382 007, India \\ e-mail: kush_2312@yahoo.com; kush2312@gmail.com
}

MS received 6 June 2017; revised 14 December 2017; accepted 1 February 2018; published online 11 May 2018

\begin{abstract}
In the present study, gas metal arc welding and flux cored arc welding were applied on SA516 Gr70 carbon steel material. Two different hybrid passes were applied, wherein flux cored wire and solid wire were applied to root pass and filler pass one by one and vice versa. Besides, two more welds of similar electrode root pass and filler pass of flux cored arc welding and gas metal arc welding were acquired. The comparative analysis was carried out in terms of macrostructure and microstructure examination, tensile testing, hardness variations, and impact testing for these classical welds and hybrid welds. The results reveal that, hybrid welds lead to better impact properties relative to classical welds. Maximum angular distortion of $2.66^{\circ}$ was reported with classical weld of gas metal arc welding with solid wire root pass and same filler pass. The maximum impact toughness of $49 \mathrm{~J} / \mathrm{m}^{3}$ was reported for flux cored root pass and solid wire filler pass at the weld zone. Maximum tensile strength of $596 \mathrm{MPa}$ was reported for hybrid weld of solid root pass and flux cored filler pass. Microstructures are reported with the presence of different acicular ferrite and grain boundary ferrite. Maximum acicular ferrite of $61 \%$ was reported with classical weld of flux cored arc welding.
\end{abstract}

Keywords. Filler; flux cored arc welding; gas metal arc welding; hybrid; properties.

\section{Introduction}

Gas metal arc welding (GMAW) is widely used technique due to its versatility, low cost consumables, high deposition rate, and high electrode efficiency. GMAW uses solid wire of consumable electrode to melt base material and solidification of it leads to the joint formation. In case of flux cored arc welding (FCAW), the solid wire of GMAW is replaced by tubular wire, wherein the flux is filled inside it, which subsequently provide benefits in terms of higher deposition rate and quality of joint. FCAW is beneficial for the additional shielding such as self-shielding of flux [1].

Concept of hybrid welding always leads additional process capabilities and improvement of joint properties [1]. Various hybrid approaches such as laser welding-GMAW [2], GMAW-plasma welding [3], laser welding-gas tungsten arc welding (GTAW) [4], laser welding-plasma welding [5], GTAW-friction stir welding (FSW) [1, 6, 7], laser welding-FSW [1] were developed and analysed for its process capabilities and joint properties. Manufacturing of pressure part generally follows hybrid combination of GTAW and SMAW or GTAW and submerge arc welding

*For correspondence in heavy engineering industries [8-10]. This hybrid approach of multiple welding processes consume more time as the set-up change and preparations are required. Hybrid approach of multiple filler wire is advantages in terms of time saving and process enhancement [8-10]. Previous studies report that, filler wires such as solid, flux cored and metal cored can be combined in different combinations to increase process capabilities and joint performances.

Recent studies are showing that, hybridization of filler wire in gas metal arc welding improves joint properties, overall cost, deposition rate, and weld bead profile. It is also reported that, all hybrid combinations are not resulting into better performance [816]. Hence, all combinations of hybrid filler wire must be studied. Apart from these studies, there are some specific studies available, which focuses on flux cored arc welding and solid wire gas metal arc welding. Liao et al [11] studied the influence of shielding gases on FCAW and GMAW for stainless steel base material. They observed that, shielding gases are not affecting the tensile properties. They reported that, the deposition rates and spatter formation are greatly affected by shielding gases in both of the processes of FCAW and GMAW. Mirza et al [12] found that, the shielding gases are important parameter which affect the properties of weld when process condition 
uses tubular cored wires and solid wire in case of GMAW. They noted that, the spray transfer, deposition rate and hydrogen content are driven by shielding gases in case of GMAW.

Specific studies on hybrid multiple filler wire are limitedly explored. Prajapati et al [8-10] experimented hybrid concepts with different root wire and filler wire. They concluded that, hybridization of filler wire improves process performance and joint properties along with cost benefits and less time consumption. Yuan et al [13] performed hybrid tandem GMAW multiple wires of solid wire and flux cored wire for the fillet joint configuration. This approach resulted into improvement of weld penetration in a significant way. Additionally, Yuan et al [13-16] reported that, deep penetration improves weld bead profile with an additional benefit of low spatter generation.

Despite these interesting studies, there is no study available which compare two different hybrid combinations such as FCAW root pass and GMAW filler pass and GMAW root pass and FCAW filler pass with classical welds of FCAW and GMAW, hitherto, to the best of authors' information. Therefore, it is worth of comparing joint properties and process performances of aforementioned combinations of hybrid welds with classical welds. Hence, in the present experimental study, the comparative analysis was carried out in terms of macrostructure and microstructure examination, tensile properties, hardness variations, and impact toughness for classical welds of GMAW and FCAW with hybrid welds FCAW root pass and GMAW filler pass and GMAW root pass and FCAW filler pass.

\section{Materials and methods}

The workpiece material of carbon steel (SA 516 Gr 70) was selected in the experimental investigation of hybrid welding and classical welding. The dimensions such as $300 \times 100 \times 10 \mathrm{~mm}$ of workpiece material were kept constant for all the welding trials. Solid wire of ER70S-6 was used for GMAW and flux cored wire of E71T-1C was used for FCAW, wherein, nominal diameter of $1.2 \mathrm{~mm}$ was kept constant. Chemical compositions and mechanical properties of base materials and filler wires are mentioned in table 1. Selection of filler wires was conducted carefully by keeping in mind nearly similar chemical compositions. Constant welding process parameters were applied to the FCAW and MCAW systems such as current (200 A), voltage $(28 \mathrm{~V})$, travel speed $(200 \mathrm{~mm} / \mathrm{min})$, shielding gas compositions (90\% argon - $10 \% \mathrm{CO}_{2}$ ), shielding gas flow rate $(25 \mathrm{l} / \mathrm{min})$ and electrode extension $(9-10 \mathrm{~mm})$ for all the experiments. The workpiece was V-grooved with $60^{\circ}$ angle and welding was performed with flat position. Four different combinations were carried out as shown in table 2. Classical welds of FCAW and GMAW consisted of
Table 1. Chemical compositions and mechanical properties of solid wire, flux cored wire and SA 516 Gr 70 base material.

\begin{tabular}{lccc}
\hline \multicolumn{3}{c}{ Chemical compositions of filler wire and base material } \\
\hline Contents & $\begin{array}{c}\text { Solid wire } \\
\text { (ER70S-6) }\end{array}$ & $\begin{array}{c}\text { Flux cored wire } \\
\text { (E71T-1C) }\end{array}$ & $\begin{array}{c}\text { Base metal } \\
\text { (SA516Gr70) }\end{array}$ \\
\hline $\mathrm{C}$ & 0.07 & 0.03 & 0.186 \\
$\mathrm{Si}$ & 0.86 & 0.56 & 0.322 \\
$\mathrm{Mn}$ & 1.44 & 1.29 & 1.112 \\
$\mathrm{P}$ & 0.014 & 0.011 & 0.014 \\
$\mathrm{~S}$ & 0.008 & 0.005 & 0.009 \\
$\mathrm{Cr}$ & 0.025 & 0.04 & 0.030 \\
$\mathrm{Ni}$ & 0.014 & 0.02 & 0.026 \\
$\mathrm{Mo}$ & 0.002 & 0.01 & 0.019 \\
$\mathrm{~V}$ & 0.002 & 0.02 & 0.001 \\
$\mathrm{Nb}$ & $\mathrm{N} / \mathrm{A}$ & $\mathrm{N} / \mathrm{A}$ & $\mathrm{Nil}$ \\
$\mathrm{Cu}$ & 0.15 & 0.01 & 0.033 \\
Mechanical properties of filler wire and base material \\
Yield strength & $427 \mathrm{MPa}$ & $605 \mathrm{MPa}$ & $446.9 \mathrm{MPa}$ \\
Tensile strength & $529 \mathrm{MPa}$ & $579 \mathrm{MPa}$ & $590.60 \mathrm{MPa}$ \\
Elongation & $26 \%$ & $31 \%$ & $24.8 \%$ \\
\hline
\end{tabular}

Table 2. Description of welding combinations.

\begin{tabular}{|c|c|c|c|}
\hline ID & Root pass & Filler pass & $\begin{array}{c}\text { Type of } \\
\text { weld }\end{array}$ \\
\hline SS & Solid wire (GMAW) & Solid wire (GMAW) & $\begin{array}{r}\text { Classic } \\
\text { weld }\end{array}$ \\
\hline $\mathrm{FF}$ & $\begin{array}{c}\text { Flux cored wire } \\
\text { (FCAW) }\end{array}$ & $\begin{array}{c}\text { Flux cored wire } \\
\text { (FCAW) }\end{array}$ & $\begin{array}{r}\text { Classic } \\
\text { weld }\end{array}$ \\
\hline SF & Solid wire (GMAW) & $\begin{array}{c}\text { Flux cored wire } \\
\text { (FCAW) }\end{array}$ & $\begin{array}{r}\text { Hybrid } \\
\text { weld }\end{array}$ \\
\hline FS & $\begin{array}{l}\text { Flux cored wire } \\
\text { (FCAW) }\end{array}$ & Solid wire (GMAW) & $\begin{array}{r}\text { Hybrid } \\
\text { weld }\end{array}$ \\
\hline
\end{tabular}

same root pass and filler pass of flux cored wire and solid wire, respectively. Besides, the hybrid welds were made by different root pass and filler pass of flux cored wire and solid wire one by another and vice versa as shown in table 2 .

The welded coupons are subjected to different inspections and analysis such as visual inspection, angular distortion measurement, macro-graphic inspection, microstructure study, tensile behaviour, bending test, impact-energy analysis and hardness distribution. These testing methods were carried out according to the standards of ASME section IX and ASTM. The angular distortion was performed with the help of dial indicator. Macro-graphic examination was carried out on cross sectional specimen that was grinded and polished with carbide grit papers of 120, 320, 800, 1000 and 5000 grades and diamond paste. The chemical etchant of $8 \%$ nital solution $\left(96 \% \mathrm{HNO}_{3}\right.$ and $4 \%$ methanol) was performed for 2-3 minutes on the 
Table 3. Actual process performance parameters.

\begin{tabular}{|c|c|c|c|c|c|c|c|c|c|}
\hline \multirow[b]{2}{*}{ Welding process ID } & \multicolumn{3}{|c|}{ Current (Amp) } & \multicolumn{3}{|c|}{ Voltage (volts) } & \multicolumn{3}{|c|}{ Heat input $(\mathrm{kj} / \mathrm{mm})$} \\
\hline & Root pass & Filler pass & Avg. & Root pass & Filler pass & Avg. & Root pass & Filler pass & Avg. \\
\hline SS & 273 & 286 & 280 & 28 & 28 & 28.1 & 2.29 & 2.41 & 2.35 \\
\hline $\mathrm{FF}$ & 273 & 282 & 277 & 27.9 & 28 & 27.95 & 1.95 & 2.29 & 2.12 \\
\hline SF & 309 & 228 & 268 & 28 & 27.9 & 28 & 2.58 & 1.98 & 2.28 \\
\hline FS & 234 & 272 & 253 & 28 & 27.9 & 28.1 & 2.28 & 2.36 & 2.32 \\
\hline
\end{tabular}

Table 4. Angular distortion under classical welds and hybrid welds.

\begin{tabular}{lccc}
\hline $\begin{array}{l}\text { Welding } \\
\text { process } \\
\text { ID }\end{array}$ & $\begin{array}{c}\text { Vertical } \\
\text { displacement } \Delta Z \\
\text { in mm }\end{array}$ & $\begin{array}{c}\text { Horizontal } \\
\text { displacement } \Delta X \\
\text { in mm }\end{array}$ & $\begin{array}{c}\text { Angular } \\
\text { distortion }(\theta)\end{array}$ \\
\hline SS & 4.98 & 100 & 2.85 \\
FF & 4.66 & 100 & 2.66 \\
SF & 4.07 & 100 & 2.33 \\
FS & 4.98 & 100 & 2.66 \\
\hline
\end{tabular}

welded specimens. The transverse cross section was prepared and machined according to the standard specimen size of tensile testing mentioned in ASME section IX. The bending tests were performed for root pass and face pass as per standard ASME section IX with mandrill diameter of 30 $\mathrm{mm}$ and $180^{\circ}$ angle. The impact energy test was conducted on sample $10 \mathrm{~mm} \times 7.5 \mathrm{~mm}$ with V-notch at temperature of $-49^{\circ} \mathrm{C}$ for the weld zone and heat affected zone (HAZ). Hardness across the cross section of the weld was noted horizontally as well as vertically at $1 \mathrm{~mm}$ indentation.

\section{Results and discussion}

The process performance output recorded by data monitoring system is presented in table 3. Apart from constant settled parameters, differences were seen in actual values of current and heat input. The current of $280 \mathrm{Amp}$ and heat input of $2.35 \mathrm{kj} / \mathrm{mm}$ were reported as maximum for classical weld of GMAW relative to the other welds. This is due to differences in the current carrying capacity of wire construction. Solid wire can carry higher current as the metallic solid part is responsible to carry current, whereas the flux cored wire contains non-metallic flux powder in a metallic tube and hence it can carry less current. On the other hand, it can be noted that, the overall balance in current and heat input were observed with both of the hybrid welds. Hybridization of solid wire and flux cored wire have compensated the current and heat input values. The angular distortion of hybrid and classical welds are measured and presented in table 4. Maximum angular distortion of $2.85^{\circ}$ was reported for classical weld of solidsolid

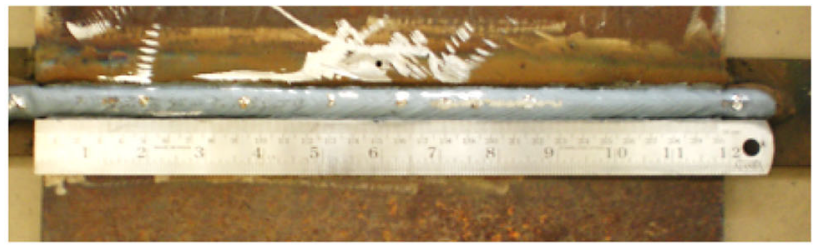

(a)

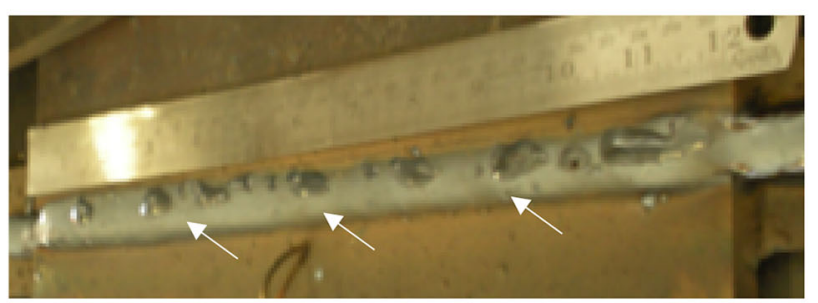

(b)

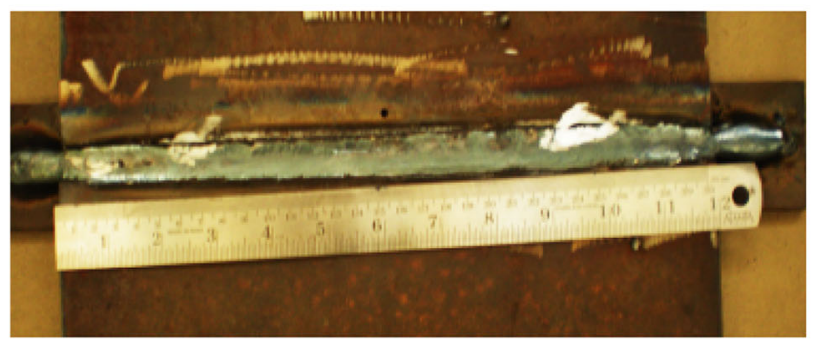

(c)

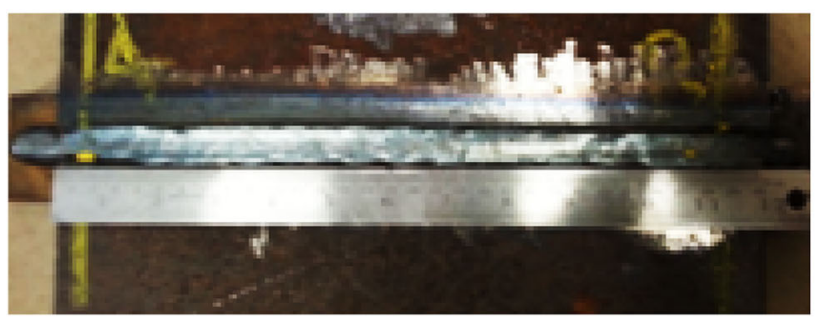

(d)

Figure 1. Visual surface inspection of classical welds and hybrid welds: (a) SS, (b) FF, (c) SF, and (d) FS.

wires as maximum heat input was observed for the same weld (table 3). Besides, the minimum angular distortion of $2.33^{\circ}$ was reported for hybrid weld of solid root pass and flux cored filler pass as the heat input was lower for this case. It is well known that, the co-efficient of thermal expansion is greatly affected by heat input values that 


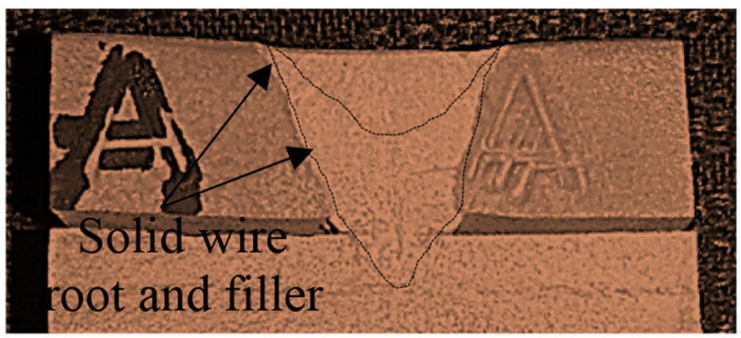

(a)

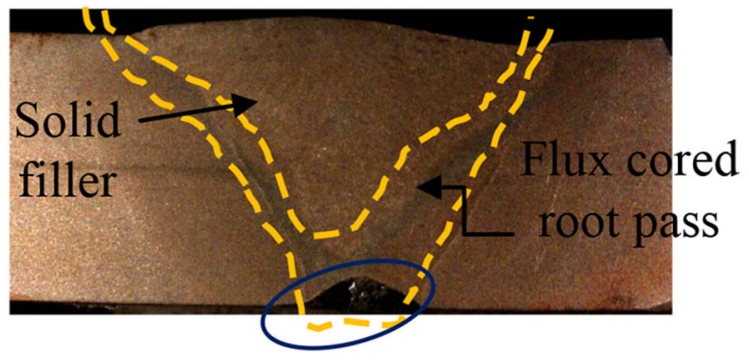

(c)

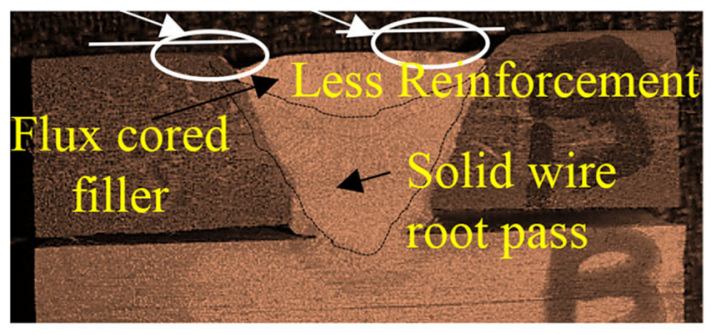

(b)

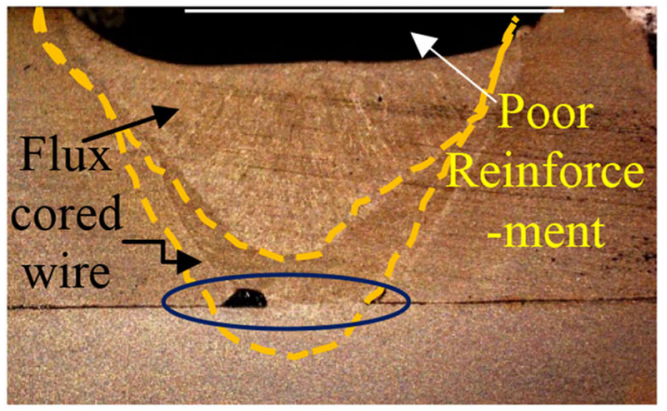

(d)

Figure 2. Macro images of classical and hybrid welds: (a) SS, (b) FS, (c) SF, and (d) FF.

consequently resulted into variations of angular distortion, which is the reason for differences in angular distortion with respect to hybrid and classical conditions. It can be stated that, hybrid combinations of solid root pass and flux cored filler pass have improved the level of angular distortion relative to the classical welds.

Visual inspection of hybrid welds and classical welds are shown in figure 1 . It can be seen that, no major defects were observed. Classical weld of flux cored root pass and filler pass is observed with chicken marks that may be because of slag formation. Slag formation is usual in flux cored filler wire that sometimes will not allow escaping of gases that in turn results into chicken marks. Other than this defect, free surface morphologies were reported.

Cross sectional macro images are shown in figure 2 for classical and hybrid welds. It can be seen that weld part is not consisted any major defects except variations in macro surface morphologies considering reinforcement, penetration and width of weld. Full penetration and reinforcement was observed with classical weld of solid-solid wires (see figure 2a). Besides, poor penetration and reinforcement was reported with classical weld of flux cored-flux cored wire (see figure 2d). Hybrid welds indicated that poor penetration and reinforcement of flux cored classical weld can be enhanced up to some level. However, hybrid weld with flux cored root pass causes less penetration while hybrid weld with solid wire root pass leads less reinforcement. This is due to electrode wire nature and construction. As it is known that, the flux cored wire is filled with flux powder that acts as shielding and forms slag at the end. This in turn reduces overall consumption of metallic material volume in the weld, which causes problems of macro surface morphologies. Besides, it is observed that the solid wire can provide more metallic material compare to the flux cored wire, which in turn leads to higher reinforcement. In case of flux cored root pass welds, the suck back effect was reported because of less metallic material is presented at the end as a part of weld. After solidification of flux, the weld part is contracted and resulted into the suck back effect.

Microstructural variations of classical welds and hybrid welds are shown in figure 3. It can be seen that, various microstructural zones were reported inside the welds. The weld part was consisted of widmanstatten ferrite, acicular ferrite and boundary ferrite zones in majority. Percentage variations of these zones are reported and mentioned in table 5. Acicular ferrite is reported higher in case of FF, SF and FS welds relative to SS weld, whereas, grain boundary ferrite is reported higher in SS weld relative to FF, SF and FS welds. The highest acicular ferrite of $60.77 \%$ was reported with classical weld of FF welds while highest grain boundary ferrite of $33.07 \%$ was reported with classical weld of SS. The reason for this may be presence of manganese and silicon elements in different proportions. These variations of acicular ferrite and grain boundary ferrite consequently influenced mechanical properties of the welds. It is also known that different constructions of electrode wires leads to variations in heat input conditions although with same process parameters. This in turn causes changes in microstructures as presented in figure 3 . 


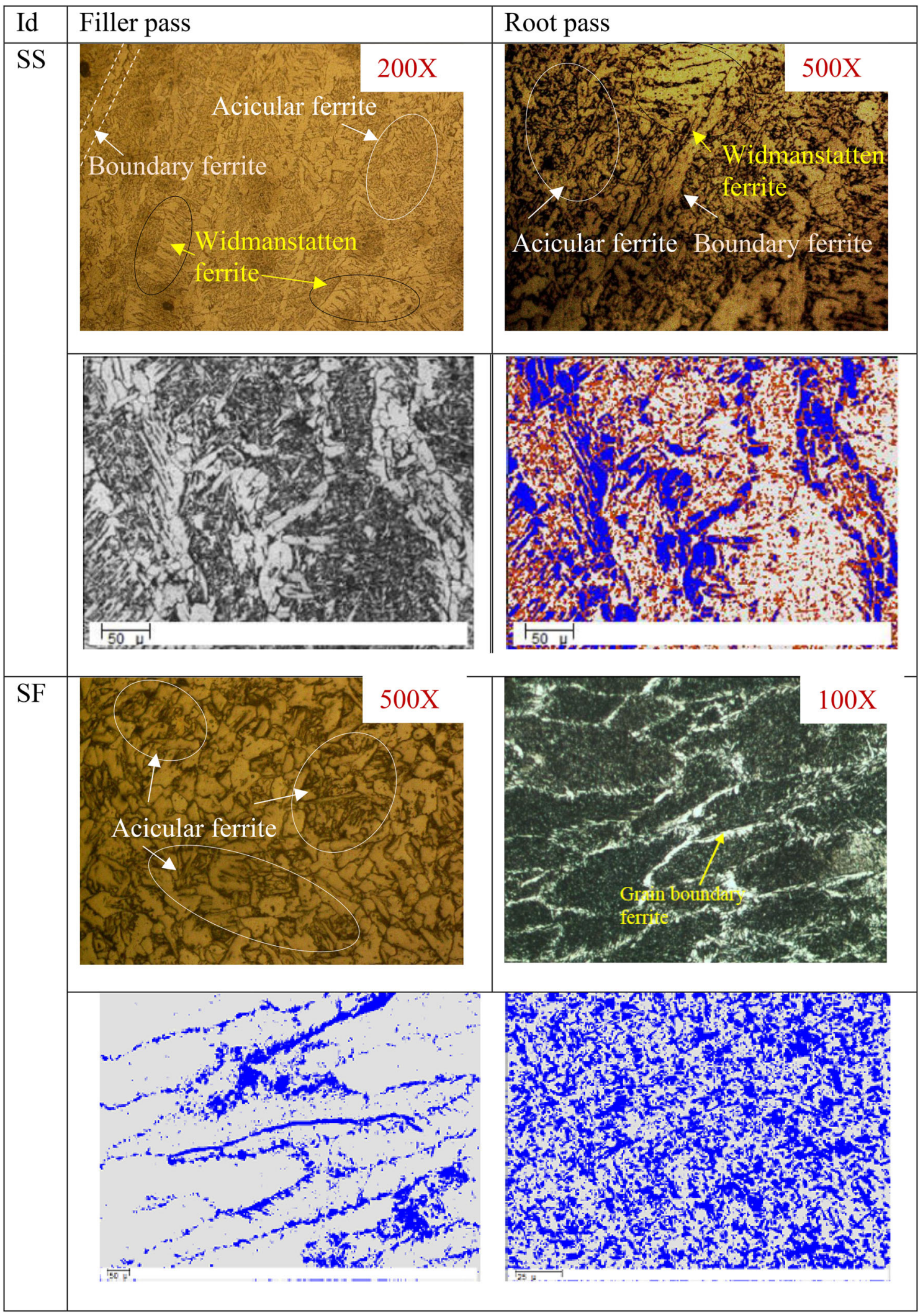

Figure 3. Microstructural images of classical and hybrid welds. 


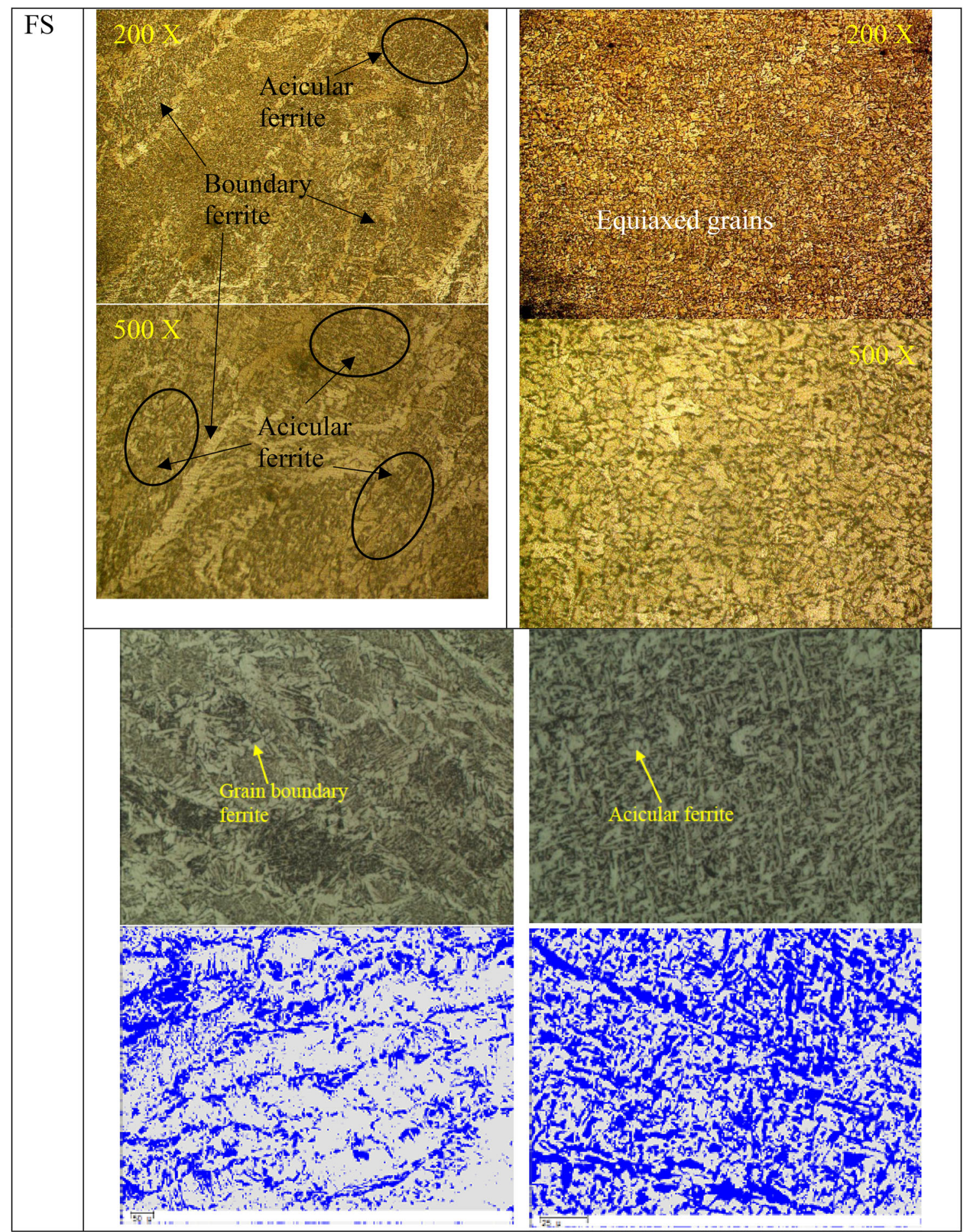

Figure 3. continued

Tensile properties such as yield strength and tensile strength are shown in figures 4 and 5, respectively. Classical weld of FF was reported with minimum yield strength of $359 \mathrm{MPa}$ and tensile strength of $565 \mathrm{MPa}$. Low tensile properties of FF weld may be because of defects reported in macrographs of the welds such as suck back and poor reinforcement as presented in figure 2. Besides, no major variations in yield strength and tensile strength are reported with other classical and hybrid welds. Maximum tensile strength of $596 \mathrm{MPa}$ and yield strength of $387 \mathrm{MPa}$ are reported for hybrid weld of SF. This is because of better macrograph as well as large content of acicular ferrite such 


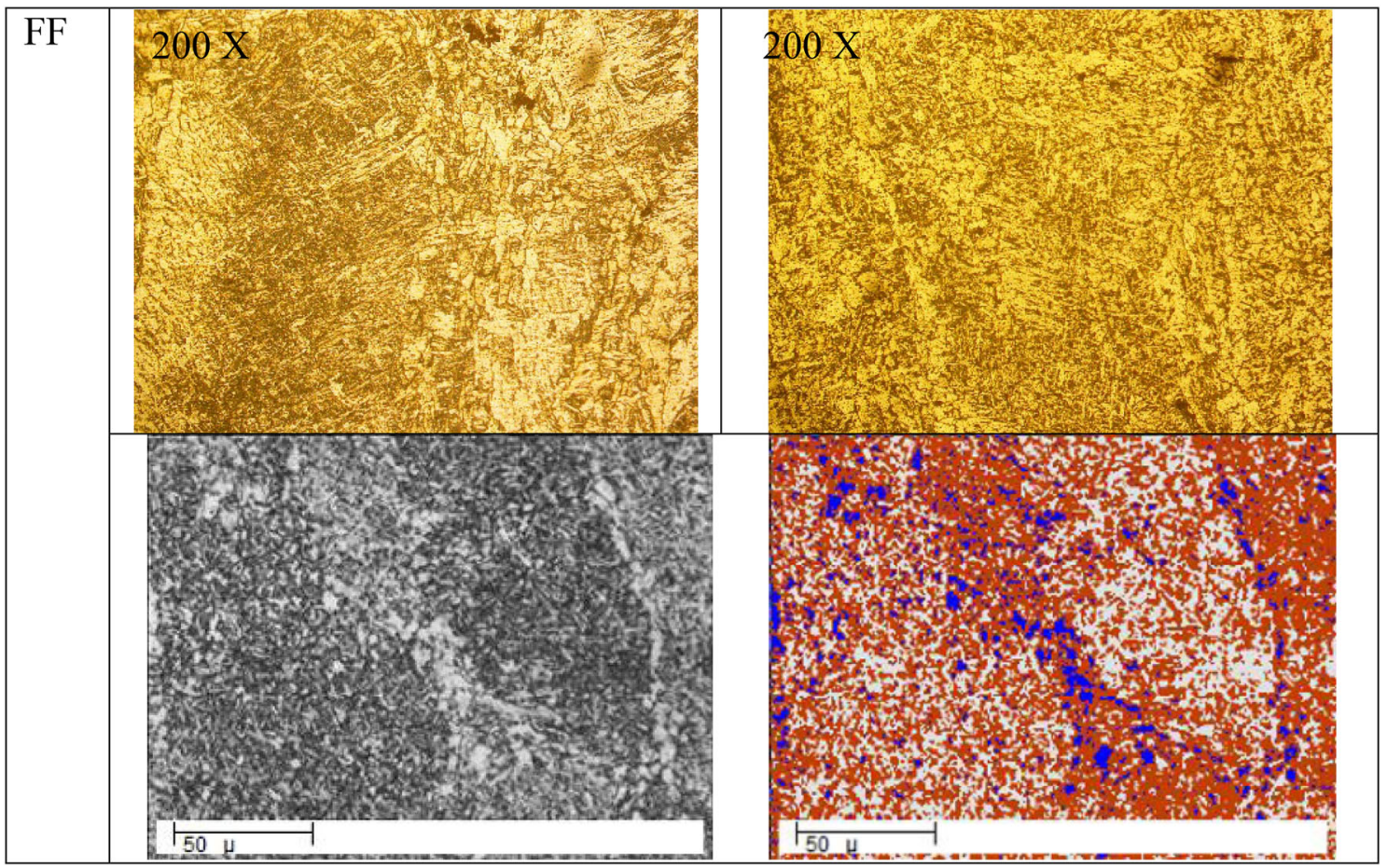

Figure 3. continued

Table 5. Identification of acicular ferrite and grain boundary ferrite based on solarized optical microscopic image.

\begin{tabular}{lcc}
\hline $\begin{array}{l}\text { Welding process } \\
\text { ID }\end{array}$ & $\begin{array}{c}\text { \% Acicular } \\
\text { ferrite }\end{array}$ & $\begin{array}{c}\text { \% Grain boundary } \\
\text { ferrite }\end{array}$ \\
\hline SS & 38.11 & 33.07 \\
FF & 60.77 & 7.34 \\
SF & 44.38 & 8.90 \\
FS & 50.37 & 10 \\
\hline
\end{tabular}

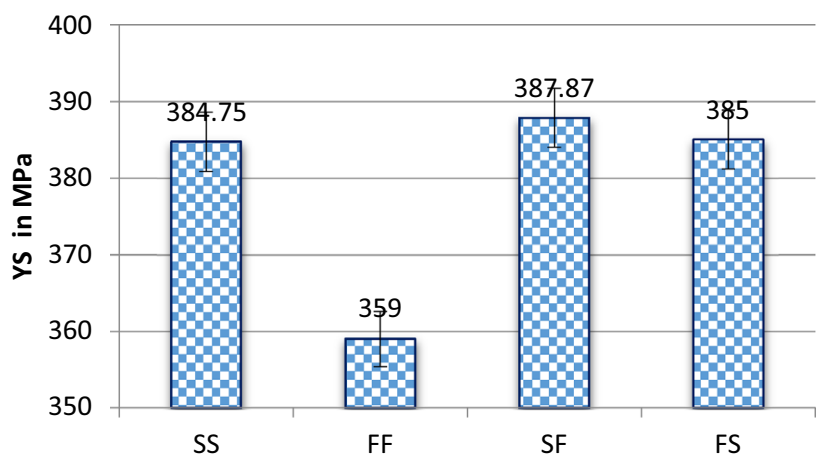

Figure 4. Yield strength of classical and hybrid welds.

as $44 \%$. Nevertheless, the acicular ferrite is also higher in case of FF and FS welds and hence no major variations in tensile properties are reported. Slightly low values of

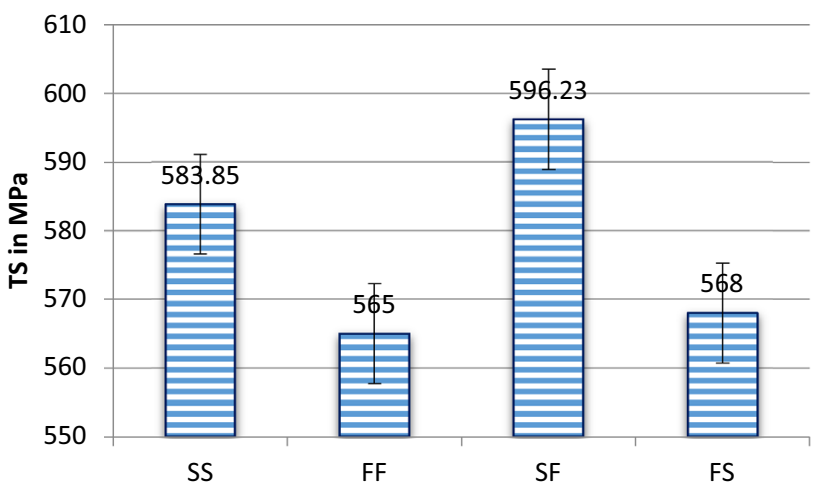

Figure 5. Tensile strength of classical welds and hybrid welds.

tensile properties are reported relative to SF weld that may be because of suck back effect presented at the root pass due to flux cored root pass. It can be stated that the hybridization of solid wire root pass and flux cored wire filler pass provide best combination of weld in terms of tensile properties. Despite having suck back defect, the welds have cleared bend tests at face and root weld surfaces as shown in figure 6. However, the grinding and machining were performed to prepare bend test sample as per standards, which have eliminated the suck back defect and thus it was not reflected in bend test results.

Impact toughness results of classical welds and hybrid welds are shown in figure 7. It can be seen that, minimum 


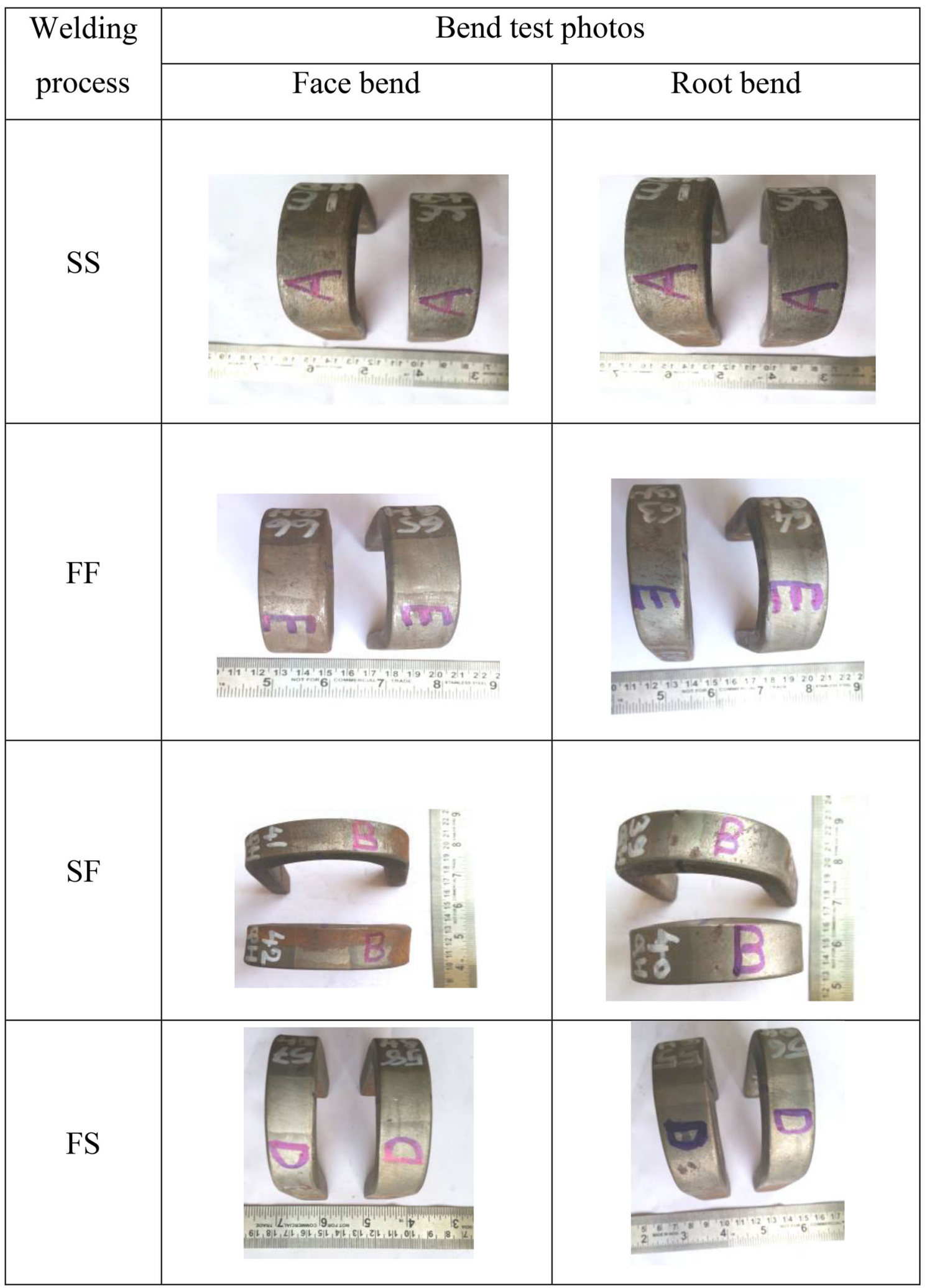

Figure 6. Bend test results of classical welds and hybrid welds.

impact toughness values of $18 \mathrm{~J} . \mathrm{m}^{-3}$ at weld and $16 \mathrm{~J} . \mathrm{m}^{-3}$ at HAZ were reported for SS classical weld whereas rest of the welds and HAZ were reported higher impact toughness.
Highest toughness of $48 \mathrm{~J} \cdot \mathrm{m}^{-3}$ at weld was reported with hybrid weld of FS this is because higher presence of acicular ferrite as reported in table 5. However, maximum 


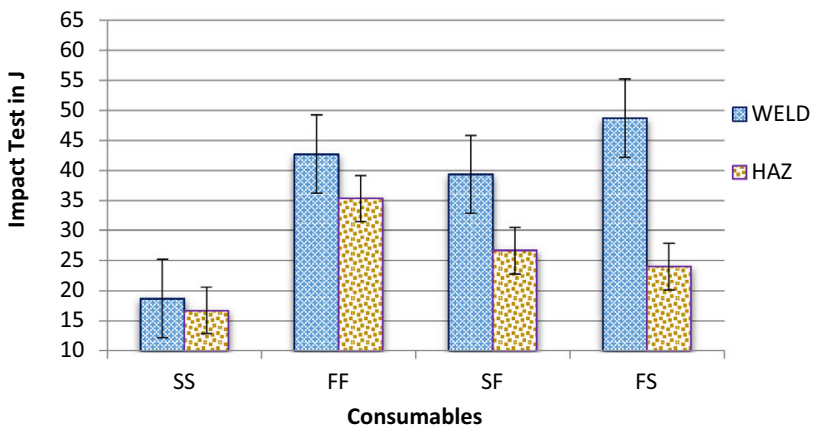

Figure 7. Impact energy for classical and hybrid welds for weld and HAZ.

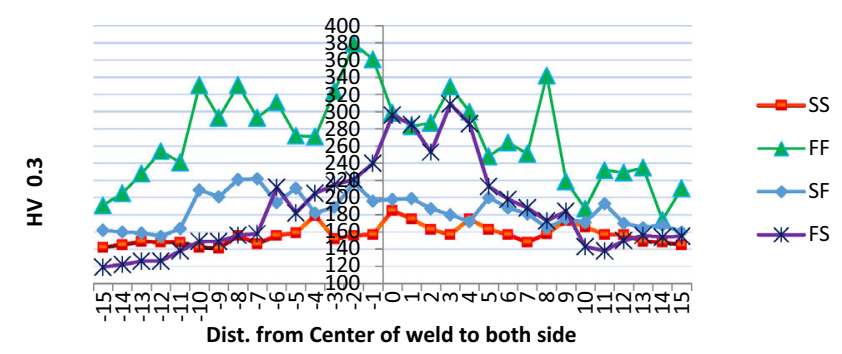

Figure 8. Hardness distribution across cross section for classical and hybrid welds.

acicular ferrite was reported for classical weld of FF, where impact toughness was observed as $42 \mathrm{~J}^{-3} \mathrm{~m}^{-3}$ at weld are and $35 \mathrm{~J}^{-3} \mathrm{~m}^{-3}$ at HAZ area. Both the areas of weld and $\mathrm{HAZ}$ are having maximum impact toughness in case of FF weld, which is due to maximum presence of acicular ferrite of $60 \%$ as mentioned in table 5 .

Hardness property is evaluated across the cross section of the welded sample and is shown in figure 8. The maximum hardness was reported for classical FF weld compare to rest of the welds of SS, SF and FS. The reason for is nothing but the presence of equiaxed fine grain microstructure as can be seen from figure 3 (FF weld). Across the cross section, no major variations were reported for classical welds of SS and FF. Besides, minor variations were observed for hybrid welds of SF and FS. This is because of minor changes in microstructures reported due to differences in the filler wire.

\section{Conclusions}

Comparative analysis of classical welds of GMAW and FCAW, and hybrid welds of GMAW-FCAW and FCAWGMAW was carried out successfully. Following conclusive statements can be fetched from the present comparative analysis.

(i) Maximum output current and heat input was reported for classical weld of GMAW. Overall balance in current and heat input was observed for hybrid welds of GMAW-FCAW and FCAW-GMAW.

(ii) Maximum angular distortion was reported with classical weld of GMAW-GMAW.

(iii) Weld morphological defects of suck back effect was reported at the root of the welds, where flux cored wire was applied as root pass.

(iv) Classical weld of GMAW-GMAW was reported with less percentage of acicular ferrite relative to the other welds. No major variations in formation of acicular ferrite were reported for the welds of FCAW-FCAW, FCAW-GMAW and GMAW-FCAW.

(v) Maximum tensile properties such as tensile strength of $596 \mathrm{MPa}$ and yield strength of $387 \mathrm{MPa}$ were reported for hybrid weld of GMAW-FCAW.

(vi) Maximum impact toughness at weld $\left(42 \mathrm{~J} . \mathrm{m}^{-3}\right)$ and

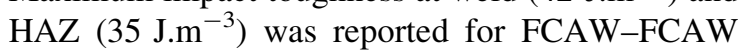
welds. Maximum toughness of weld $\left(48 \mathrm{~J} \cdot \mathrm{m}^{-3}\right)$ was reported with FCAW-GMAW weld.

(vii) Maximum hardness across the cross section was reported to be highest in case of FCAW-FCAW welds when compared to rest of the welds.

\section{Acknowledgements}

The authors are thankful to the Department of Science and Technology (DST), India The facilities were developed under the sanctioned project SR/FTP/ETA-19/08 and were used in this investigations.

\section{References}

[1] Mehta K 2017Advanced joining and welding techniques: an overview. In: Advanced Manufacturing Technologies, Gupta K (Ed.), Springer International Publishing, Cham. pp. 101-136. https://doi.org/10.1007/978-3-319-56099-1_5

[2] Li C, Muneharua K, Takao S and Kouji H 2009 Fiber laserGMA hybrid welding of commercially pure titanium. Mater. Des. 30: 109-114

[3] Zielińska S, Musioł K, Dzierżęga K, Pellerin S, Valensi F, de Izarra C and Briand F 2007 Investigations of GMAW plasma by optical emission spectroscopy. Plasma Sources Sci. Technol. 16: 832

[4] Song G, Liu L and Wang P 2006 Overlap welding of magnesium AZ31B sheets using laser-arc hybrid process. Mater. Sci. Eng. A. 429: 312-319

[5] Bagger C and Olsen F O 2005 Review of laser hybrid welding. J. Laser Appl. 17: 2-14

[6] Mehta K P and Badheka V J 2017 Hybrid approaches of assisted heating and cooling for friction stir welding of copper to aluminum joints. J. Mater. Process. Technol. 239: 336-345

[7] Mehta K P and Badheka V J 2016 A review on dissimilar friction stir welding of copper to aluminum: process, properties, and variants. Mater. Manuf. Process. 31: 233-254 
[8] Prajapati P, Badheka V J and Mehta K P 2016 Hybridization of filler wire in multi-pass gas metal arc welding of SA516 Gr70 carbon steel. Mater. Manuf. Process. 33: 315-322

[9] Prajapati P and Badheka V J 2017 Hybrid approach of fluxcored root pass with subsequent pass of metal-cored or solid wire in multifiller gas metal arc welding. Metallogr. Microstruc. Anal. 6: 553-560

[10] Prajapati P and Badheka V J 2017 Investigation on various welding consumables on properties of carbon steel material in gas metal arc welding under constant voltage mode. Sādhanā. 42: 1751-1761

[11] Liao M T and Chen W J 1999 A comparison of gas metal arc welding with flux-cored wires and solid wires using shielding gas. Int. J. Adv. Manuf. Technol. 15: 49-53

[12] Mirza R M and Gee R 1999 Effects of shielding gases on weld diffusible hydrogen contents using cored wires. Sci. Technol. Weld. Join. 4: 104-111
[13] Yuan Y, Yamazaki K and Suzuki R 2016 Relationship between penetration and porosity in horizontal fillet welding by a new process "hybrid tandem MAG welding process". Weld. World 60: 515-524

[14] Yuan Y, Yamazaki K, Suzuki R, Tashiro S and Tanaka M 2012 Development of deep penetration \& low spatter hybrid tandem GMAW process (part1). In: Preprints of the National Meeting of JWS, vol. 90, pp. 8-9

[15] Yuan Y, Yamazaki K, Suzuki R, Tashiro S and Tanaka M 2013 Development of deep penetration \& low spatter hybrid tandem GMAW process (part2). In: Preprints of the National Meeting of JWS, vol. 92, pp. 16-17

[16] Yuan Y, Yamazaki K, Suzuki R, Tashiro S and Tanaka M 2014 Development of deep penetration \& low spatter hybrid tandem GMAW process (part 3: porosity resistance). In: Preprints of the National Meeting of JWS, vol. 94, pp. $124-125$ 